\title{
MACAÚBA: PALMEIRA DE EXTRAÇÃO SUSTENTÁVEL PARA BIOCOMBUSTÍVEL
}

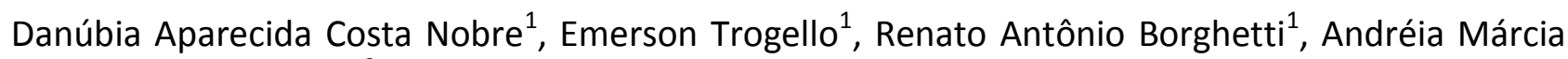
Santos de Souza David ${ }^{2}$

${ }^{1}$ Universidade Federal de Viçosa - Viçosa - MG, Universidade Estadual de Montes Claros - Montes Claros - MG. ${ }^{2}$

\section{RESUMO}

A busca por processos sustentáveis é crescente em diferentes meios, porém, é na substituição de combustíveis fósseis por combustíveis renováveis que se tem o maior enfoque. Encontrar culturas que apresentem potencial para produção de óleo e que tenham alto rendimento é um dos grandes gargalos ao crescimento dos biocombustíveis. Esta revisão literária tem como objetivo contribuir com informações a respeito de uma palmeira produtiva e eficiente na produção de óleo, a macaúba. Esta palmeira apresenta uma produtividade média de frutos de $15 \mathrm{t} \mathrm{ha}^{-1}$ e rendimento médio em óleo de $4 \mathrm{t} \mathrm{ha}{ }^{-1}$, bem superior ao rendimento das oleaginosas mais comumente utilizadas, como a soja, a mamona, o girassol, o algodão e o amendoim, que apresentam produtividade média de $1 \mathrm{t} \mathrm{ha}^{-1}$. Desta forma, a macaúba apresenta potencial para produção sustentável de biocombustíveis e de extrativismo familiar, além de, ser encontrada em praticamente todas as regiões do Brasil.

Palavras-chave: agricultura familiar; biocombustíveis; sustentabilidade.

\section{MACAÚBA: SUSTAINABLE PALM EXTRACTION FOR BIOFUEL}

\begin{abstract}
The search for sustainable processes is growing in different media, however, is the replacement of fossil fuels with renewable fuels that have greater focus. Find cultures with potential for oil production and have high performance is a major bottleneck to the growth of biofuels. This literature review aims to contribute information about a productive and efficient in the production of palm oil, the macauba. This palm has an average fruit yield of $15 \mathrm{t} \mathrm{ha}^{-1}$ and average yield of $4 \mathrm{t}$ $\mathrm{ha}^{-1}$ oil well above the yield of the most commonly used oil, such as soybean, castor bean, sunflower, cotton and peanuts, which has average productivity of $1 \mathrm{t} \mathrm{ha} \mathrm{a}^{-1}$. Thus, macauba shows potential for sustainable biofuel production and extraction of family, and be found in virtually all regions of Brazil.
\end{abstract}

Keywords: family farming; biofuels; sustainability. 


\section{INTRODUÇÃO}

É visível o aumento do uso de combustíveis fósseis nas últimas décadas, o que pode culminar no esgotamento destas reservas. Estudos realizados por Schuchardt et al. (2001) indicam que as reservas de petróleo mundiais tendem a se esgotar em cerca de 100 anos. Já Ramos et al. (2011) afirmam que novas jazidas estão sendo descobertas, o que cria uma incerteza sobre a verdadeira extensão e viabilidade desta fonte de energia.

Além das incertezas sobre as reservas deste produto, tem-se que considerar ainda os aspectos ambientais. Segundo dados da ONU (2011), o uso de combustíveis fósseis é a principal causa do aumento da concentração de gases do efeito estufa na atmosfera, podendo elevar a temperatura média da Terra de 1,8 a 4,0 ํㅡ até o ano de 2100, acelerando o derretimento das geleiras, elevando o nível do mar e provocando intensos furacões.

Diante dessas incertezas sobre as reservas de petróleo e dos problemas ambientais oriundos de sua utilização, cabe salientar ainda os problemas de ordem social. Segundo projeções da ONU, alcançaremos no ano de 2050 uma população constante de aproximadamente 9,1 bilhões de pessoas, as quais necessitarão consumir produtos da mesma ordem dos consumidos atualmente. Desta forma, cria-se uma enorme demanda de crescimento da produção mundial de todas as culturas agrícolas, crescimento este, que deve ser embasado em uma produção sustentável e com a utilização de energias limpas e renováveis.

Aliando-se a crise do petróleo, a crescente demanda por combustíveis e a constante preocupação com o meio ambiente e sustentabilidade, redireciona-se a busca por fontes de energia alternativa, ou tidas como renováveis (POUSA et al., 2007; SUAREZ, MENEGUETTI, 2007).

Segundo Suarez et al. (2007), a substituição de derivados de petróleo por matérias primas tidas como renováveis, para a produção de combustíveis, é o grande enfoque das pesquisas. A biomassa pode abranger um papel de destaque, uma vez que, a mesma, é de natureza renovável, e apresenta ampla disponibilidade, biodegradabilidade e baixo custo.

A produção de biocombustíveis derivados de fontes naturais e renováveis como os vegetais, torna-se viável, por ser capaz de reduzir em até $78 \%$ as emissões poluentes de gás carbônico, considerando-se a reabsorção pelas plantas. Além disso, reduz em até $90 \%$ as emissões de fumaça e, praticamente elimina as emissões de óxido de enxofre (ALBUQUERQUE et al., 2008). 
O dilema entre a segurança alimentar e energética é outra questão que permeia a utilização de biomassa para produzir combustível. O incentivo à produção dos biocombustíveis tidos como de primeira geração (álcool e biodiesel), segundo alguns pesquisadores, tem deslocado áreas tradicionalmente utilizadas para o cultivo de alimentos para a produção de insumos destinados à indústria dos biocombustíveis, o que vem aumentando a preocupação da crise mundial dos alimentos (SUAREZ et al., 2009).

Atualmente, as matérias-primas vegetais para produção de biodiesel, no país, são originárias de fontes como soja, mamona, girassol, algodão e amendoim. Destas, apenas a soja responde por mais de 75\% da oferta destinado ao PNPB - Programa Nacional de Produção e Uso de Biodiesel. No entanto, essas oleaginosas em destaque, apresentam rendimento de óleo abaixo de 1.000 litros por hectare, enquanto que, espécies de palmeiras podem gerar pelo menos, três vezes mais, além de serem aproveitadas para a cogeração de energia (COSTA, MARCHI, 2008).

Diante do exposto, a palmeira Macaúba (Acrocomia aculeata (Jacq.) Lood. ex Mart) apresenta grande potencial para produção de óleo com vasta aplicação nos setores industriais e energéticos, com vantagens sobre outras oleaginosas, principalmente com relação à sua maior rentabilidade agrícola e produção total de óleo (ROLIM, 1981). Desta forma, a macaúba se caracteriza como uma espécie com qualidades importantes do ponto de vista natural, ecológico e principalmente sócioeconômico (NUCCl, 2007).

A planta é arborescente perene, frutífera, nativa de floresta tropical, tipicamente brasileira e com ampla distribuição geográfica. São palmeiras monóicas e autocompatíveis podendo realizar fecundação cruzada entre indivíduos diferentes, revelando sistema reprodutivo misto (SCARIOT et al., 1995).

Em algumas localidades ocorre em populações densas, o que caracteriza a espécie como oligárquica. Lleras \& Coradin (1985) estimaram uma produtividade de 5 toneladas de óleo do tipo oléico-palmítico e 1,4 toneladas de óleo do tipo laúrico de plantios com uma densidade de 200 plantas $\mathrm{ha}^{-1}$. Tal produtividade se compara favoravelmente com a produtividade do dendê (Elaeis guineensis), que é a cultura com maior produção de óleo por hectare cultivado. Vale ressaltar que a macaúba se desenvolve bem em ambientes mais secos do que aqueles que o dendê suporta, sendo portanto, mais uma característica favorável à sua produção. Diante disso, a palmeira macaúba é vista como a cultura com o segundo maior potencial de produção de óleo entre as oleaginosas (TEIXEIRA, 2005). 
A macaúba é importante para fortalecer a cadeia de biocombustível e promove a geração de coprodutos. A viabilização das potencialidades dessa espécie fortalece a economia e a agricultura familiar, diante da elevada busca por novas culturas e sua produção.

\section{REVISÃO DE LITERATURA}

\section{Aspectos taxonômicos e botânicos}

A espécie Acrocomia aculeata, é constituída por apenas duas espécies - $A$. aculeata (Jacq.) Lodd. ex Mart. e A. hassleri (B. Rodr.) W. J. Hahn, que diferem basicamente pelo tamanho dos indivíduos e por sua localização geográfica. Em termos taxonômicos, a A. aculeata (Jacq.) Lodd. ex Mart. está classificada no reino: Plantae; divisão: Magnoliophyta; classe: Liliopsida; subclasse: Arecidae; ordem: Arecales; família: Arecaceae; gênero: Acrocomia e espécie: Acrocomia aculeata (NUCCl, 2007).

As inflorescências amareladas apresentam-se agrupadas em cachos pendentes de até $80 \mathrm{~cm}$ de comprimento e protegidas por uma espata que pode atingir até dois metros. As flores são pequenas, unissexuais ou de ambos os sexos presentes numa mesma inflorescência, as flores masculinas nascem no topo da inflorescência, enquanto as femininas situam-se na base. A floração ocorre quase o ano todo com maior intensidade de outubro a janeiro. Estas inflorescências são andróginas com marcada protoginia. A polinização ocorre principalmente por besouros, com o vento desempenhando um papel secundário. Os principais polinizadores são Andranthobius sp. (Curculionidae), Mystrops of mexicana (Nitidulidae) e Cyclocephala forsteri (Scarabaeidae). Mesmo a espécie sendo autocompatível e a gitonogamia (polinização cruzada entre flores vizinhas, de uma mesma planta) respondendo por uma significativa porcentagem da produção de frutos, a xenogamia, polinização cruzada entre indivíduos diferentes, é responsável por muito do sistema reprodutivo. As palmeiras são arborescentes perenifólias, heliófitas e monoicas (SCARIOT et al., 1991; LORENZI, 2002).

Os frutos são globosos, epicarpo lenhoso verde-amarelo, com 3,5 a 5,0 cm, com mesocarpo amarelado, fibrosomucilaginoso e comestível (LORENZI, 2006).

Andrade et al. (2006), relatam que o fruto maduro é uma dupla esfera ligeiramente achatada, com 0 maior diâmetro variando de 3,0 a $6,0 \mathrm{~cm}$, é liso, de coloração marrom-amarelada quando maduro e possui um epicarpo que se rompe facilmente na maturidade. Cada fruto contém uma amêndoa oleaginosa, contendo de um a três embriões viáveis, envolvida por um endocarpo rígido. Os frutos fornecem óleo, além da geração de coprodutos como a 
farinha comestível, a torta forrageira e o combustível de alto poder calorifico (carvão ativado) obtido pelo endocarpo (SCARIOT et al., 1991; LORENZI, 2002).

Um dos grandes problemas da cultura é a heterogeneidade do material existente em condições naturais, porque, além de, existir uma grande variação genética, há também uma mistura de idades das palmeiras; tornando sua produtividade total baixa, e aumentando consideravelmente $\mathrm{o}$ trabalho de colheita dos frutos, já que apresentam maturação desuniforme. Salis e Mattos (2009) relatam que a macaúba apresenta frutos verdes o ano todo, e os frutos maduros são encontrados de setembro a dezembro.

De modo geral, o número de cachos e de frutos por planta de macaúba é menor nos anos iniciais de produção, quando comparado com as plantas em plena maturidade (LORENZI, NEGRELLE, 2006). Neste sentido, pode-se afirmar que como mecanismo de defesa, a macaúba quando se encontra em áreas de baixa densidade populacional, geralmente, passa a produzir mais frutos para garantir a manutenção da espécie na área.

Conforme Lorenzi (2006), a espécie é representada por palmeiras de caule simples, cujo estipe pode atingir de 10 a $15 \mathrm{~m}$. Os caules ou troncos das palmeiras são nomeados de estipe ou estípite, podendo apresentar formas, tamanhos, volumes e texturas variados, terminando em um meristema apical, onde ocorre o ponto de crescimento da planta, sendo que este órgão vital fica protegido por folhas em desenvolvimento, abrigado externamente pelas bainhas das folhas (SODRÉ, 2005). No caso da macaúba, pode-se perceber que palmeiras maiores apresentam menor diâmetro, o que pode ser explicado pela presença de estipe recoberto por reminiscências das bainhas espinhentas em palmeira quando jovem.

As folhas de macaúba são classificadas como do tipo composta e estão divididas em folíolos ou pinas, lembrando o desenho de uma pena de ave. Os folíolos partem da raque ou nervura central da folha, o que ajuda na identificação da palmeira. Quanto à inserção na raque, os folíolos se dispõem em planos diferentes, ou seja, estão dispostos em ângulos diversos, proporcionando à folha um aspecto plumoso e muito decorativo, sendo típico da Acrocomia aculeata (SODRÉ, 2005). Segundo Lorenzi (2006), as folhas são em número de 10 a 30 por planta; pinadas e irregularmente dispostas e inseridas em planos diferentes ao longo da raque.

\section{Propagação da espécie}

Apesar de atualmente já existirem pesquisas em torno da macaúba e do seu 
potencial produtivo, a espécie ainda é explorada de forma extrativista. A implantação de cultivos comerciais de macaúba é dificultada pela pronunciada dormência de suas sementes. Este processo é muito lento e irregular, podendo levar de um a dois anos para a semente germinar, o que atrasa a entrada da planta na fase produtiva (BANDEIRA， 2008; LORENZI, NEGRELLE, 2006), além de ser altamente susceptível à deterioração em função do elevado teor de óleo presente na semente (HIANE et al., 2005). Portanto, é de fundamental importância estudos sobre os métodos de propagação desta espécie, com objetivo de elevar a produção, deixando de ser palmeira de cunho extrativista para tornar-se cultivável. Neste sentido, a avaliação da qualidade da semente de macaúba pode contribuir para o avanço do conhecimento necessário à domesticação da espécie (RIBEIRO et al., 2010).

A Universidade Federal de Viçosa desenvolveu uma técnica que possibilita taxa de germinação de 60 - 80\% (Universidade Federal de Viçosa, 2009). Este procedimento foi licenciado à empresa Acrotech, localizada em Viçosa - Minas Gerais, que atualmente é a única fornecedora de sementes de macaúba pré-germinadas.

Bicalho et al. (2011) desenvolveram uma técnica em que as sementes completam o processo de germinação em 28 dias, as quais em seguida são tranferidas para substrato comercial onde permanecem durante 2 meses para formação das mudas. Após 6 a 8 meses no viveiro, as plantas podem ser transferidas à condições de campo, com sucesso de $97 \%$ no seu estabelecimento. Atualmente outras técnicas tem sido empregadas, como a propagação clonal e a cultura de tecidos, buscando a otimização e agilidade na formação de mudas.

Diante do exposto, assim como o desenvolvimento de outras técnicas que facilitem o manejo da palmeira, espera-se que a macaúba torne-se cultivável e atenda a atual demanda da agricultura por culturas fornecedoras de biocombustiveis no país, fortalecendo a cadeia produtiva e a agricultura local.

\section{Distribuição geográfica}

A palmeira macaúba é arborescente perene, frutífera nativa, tipicamente brasileira e com ampla distribuição geográfica em território brasileiro. Ocorre nos Estados do Ceará, Minas Gerais, Mato Grosso, Mato Grosso do Sul, São Paulo e por toda região Sul, tendo povoamentos naturais em quase todo território, mas com concentrações populacionais expressivas em Minas Gerais, Goiás, Mato Grosso e Mato Grosso do Sul, sendo amplamente espalhada pelas áreas de Cerrado (BHERING, 2009). 
Além da diversificação da espécie, a ocorrência em quase todas as regiões do Brasil resultou na multiplicidade de denominações vulgares e regionais da palmeira, embora todas elas fossem referentes ao gênero Acrocomia e à mesma palmeira macaúba. Na região central do Brasil, a palmeira é mais conhecida como bocaiúva; no Pará e na Ilha de Marajó, é mais conhecida como mucajá, camajá, mucujá e macajá; em algumas regiões do Nordeste, é mais conhecida como camaíba e macajuba; nas demais regiões do Brasil, a palmeira recebe várias outras denominações, como macaíba, macaúba, bocaiúva, embocaiúva, coco baboso, coco espinho, coco de catarro, caiol e macajira. Apresenta grande dispersão no Brasil e em países vizinhos como Colômbia, Bolívia e Paraguai (SCARIOT et al., 1995).

No Estado de Minas Gerais, Motta et al. (2002) relaciona a ocorrência de macaúba segundo os atributos climáticos, e verifica que regiões relativamente mais quentes $\mathrm{e}$ mais secas como Coração de Jesus e Brasília de Minas têm elevada produção e número de plantas, porém, quando comparadas com outras regiões, as diferenças macroclimáticas regionais não chegam a representar um fator limitante à ocorrência e à produção da macaúba.

Faz-se necessário a busca por mais informações e tecnologias acessíveis acerca da produção de macaúba, atingindo assim, o maior número de regiões brasileiras a serem beneficiadas com a extração sustentável dessa palmeira.

\section{Usos e potencialidades da macaúba}

Embora os frutos e coprodutos da macaúba ainda sejam pouco aproveitados comercialmente, alguns estudos buscam redescobrir as antigas potencialidades da palmeira, visando acrescentar conhecimentos sobre as propriedades da planta e de seu fruto. Sabe-se hoje que a macaúba é uma frutífera cujas todas as partes têm utilidades $\mathrm{A}$ polpa que reveste as amêndoas dos cocos desta palmeira produz grandes quantidades de óleo, que é destinado, principalmente, à indústria de sabões, sendo também empregado na culinária e na medicina caseira (MOLLET et al., 2000; LORENZI, NEGRELLE, 2006). A polpa ainda pode ser consumida in natura ou na forma de refrescos, doces, sorvetes, panificação e outros (HIANE et al., 2006).

O óleo transparente e incolor obtido a partir da amêndoa dos cocos, além de possuir boa rentabilidade, é fino e comestível, podendo substituir perfeitamente o azeite de oliva e entre outras possibilidades pode ser utilizado como fonte de matéria-prima para a extração comercial de óleo (LORENZI, NEGRELLE, 2006). 
O tronco ou estipe é utilizado no meio rural como moirão, ripa, caibro e calha; as folhas e novamente os frutos, principalmente nos períodos de seca prolongada, podem ser utilizadas na alimentação dos ruminantes estimulando a lactação (NUCCl, 2007). Os folíolos servem para confecção de fibras têxteis que se transformam em linho de cor branco-esverdeado, fino, macio, mas muito resistente empregado na fabricação de linhas de pesca, cordas, cordões e tecidos para redes. Outro coproduto de grande interesse é o endocarpo, que representa, mais ou menos, $31 \%$ em peso do total do coco, e em virtude de seu elevado poder calorífico (5104 kcal $\mathrm{kg}^{-1}$ ) ressalta a importância de sua utilização como combustível, quer na forma direta, quer na forma carbonizada, ou ainda na construção civil como substituto da brita. Ainda com os resíduos da amêndoa, tem-se a torta, que pode ser utilizada na alimentação humana e animal, devido ao percentual elevado de proteínas, teor de fibra em detergente neutro (FDN) próximo de 60,0\% e extrato etéreo próximo a 10\% (BARRETO, 2008).

Os frutos são formados por cerca de $20 \%$ de casca, $40 \%$ de polpa, $33 \%$ de endocarpo e $7 \%$ de amêndoa. Os teores de óleo são ligeiramente maiores na polpa (60 \%), em relação à amêndoa (55\%). Assim como no dendê, são extraídos dois tipos de óleo da macaúba. Da amêndoa é retirado um óleo fino que representa em torno de $15 \%$ do total de óleo da planta, rico em ácido láurico (44\%) e oléico (26\%), tendo potencial para utilizações nobres como na indústria alimentícia, farmacêutica e de cosméticos. 0 óleo extraído da polpa do fruto é dominado por ácido oléico (53\%) e palmítico (19\%), e têm boas características para o processamento industrial, tendo maior potencial para a fabricação de biodiesel (BHERING, 2009).

Embora tenha várias potencialidades de utilização, é o fruto da macaúba o produto economicamente mais representativo da palmeira. A polpa do coco (adocicada e aromática) é muito apreciada pelas crianças, já na ração animal, a mesma apresenta maior emprego na engorda de suínos. A torta da polpa pode ser utilizada como adubo e combustível para caldeiras, enquanto o farelo da amêndoa tem ótimo índice de proteína e pode ser utilizado na composição de rações para animais. A casca do fruto é utilizada em fornalhas, fogões domésticos e em escala industrial para a produção de carvão. Coprodutos como a cinza estão sendo incorporados ao concreto na construção civil para minimizar o uso de cimento (MACHADO et al., 2010).

Em função de suas várias aplicabilidades, esta espécie é tida como de alta potencialidade para geração de renda (LORENZI, 2006). No entanto, ainda há a 
escassez de informações botânicas, ecológicas e agronômicas que possibilitem a implantação de sistemas de cultivo ou manejo sustentável desta espécie.

\section{Biodiesel e agricultura familiar}

A segurança energética é um dos principais desafios deste século no mundo. 0 aumento da população mundial e do consumo per capita, associados ao problema da mudança climática, ensejam a necessidade de ações mais coordenadas e sustentáveis, em seus aspectos ambientais, sociais e econômicos. Nesse sentido, o Brasil tem muito a contribuir, pois possui uma matriz energética com $46 \%$ de fontes renováveis, num mundo que só utiliza $15 \%$. Isso faz com que o país possua uma posição de destaque no cenário mundial, principalmente por sua forte estratégia em agroenergia, que representa mais da metade dessa fonte renovável (BRASIL, 2009).

A capacidade de empregar óleos vegetais como óleo combustível em substituição ao óleo diesel despertou o interesse do governo brasileiro, o qual criou através do Ministério de Ciência e Tecnologia - MCT, o Programa Brasileiro de Biodiesel PROBIODIESEL. Como o Brasil tem ampla disponibilidade de óleos vegetais, esta tecnologia representa um grande potencial econômico.
A macaúba é de ampla distribuição geográfica e com qualidades que a tornam importante, pois seus frutos são uma valiosa fonte de óleo vegetal, proporcionando vantagens ambientais, econômicas e sociais. A cultura torna-se uma importante matéria prima para a produção de biocombustiveis, além disso, o óleo apresenta alto valor de mercado em função da multiplicidade de uso industrial (TEIXEIRA, 2005; NUCCI, 2007).

Segundo Manfio et al. (2012), a cultura da macaúba se apresenta com grande importância socioeconômica, uma vez que, em sua maioria é produzida por produtores familiares. Em contrapartida à sua grande importância, ainda se encontra baixas produtividades no cultivo da macaúba, devido ao sistema de extrativismo (WANDECK, JUSTO, 1998), ou mesmo pelo cultivo utilizando-se populações heterogêneas, com amplas características variáveis e dificuldades de manejo e colheita (MOTTA et al., 2002).

\section{Espécies oleaginosas como a} macaúba, tornam-se uma ferramenta relevante para auxiliar a erradicação da miséria no país. As famílias que vivem nas regiões semiáridas, sofrendo com as péssimas condições socioeconômicas, podem ser beneficiadas através de projetos para inclusão social e o desenvolvimento regional, especialmente via geração de emprego e renda. Estes devem ser os princípios básicos 
das ações direcionadas ao biodiesel, sendo a produção e consumo promovidos de forma descentralizada e não-excludente em termos de rotas tecnológicas e matérias-primas utilizadas (BIODIESELBR, 2006).

O biodiesel contribuirá para a redução da poluição atmosférica, sendo uma tecnologia economicamente competitiva, promovendo o desenvolvimento sócioeconômico de muitas regiões, através da geração de empregos e renda, reduzindo correntes migratórias internas por contribuir com a fixação das famílias no campo, além de reduzir a dependência externa do país.

\section{Importância de se estudar a espécie}

Em razão dos elevados teores de óleo encontrados na espécie ( $26 \%$ de teor de óleo no cacho e $22 \%$ no farelo), altas produtividades médias de frutos $\left(15 \mathrm{t} \mathrm{ha}^{-1}\right) \mathrm{e}$ elevado rendimento médio em óleo ( $4 \mathrm{t} \mathrm{ha}^{-1}$ ) (BRASIL, 2009), a macaúba tem potencial para a produção de biodiesel e forte tendência para elevar a economia no setor de óleos vegetais.

Estudos demonstram que percentagem de óleo na polpa varia de 19,5 a $27,2 \%$ enquanto que na amêndoa varia de 32,9 a $50,6 \%$, já quanto ao rendimento de óleo total extraído (polpa e amêndoa) em relação ao fruto inteiro varia de 12,2 a 18,3\% (PEREIRA et al., 2009). Isto demonstra que a produtividade da planta e o rendimento de óleo dos frutos é fator importante a ser incluído nas bases de estudo do biodiesel.

Estudos sobre a morfologia das plantas e dos frutos de macaúba são importantes para viabilizar a produção com a finalidade de extração de óleo, além de outros estudos voltados à exploração de outros potenciais dessa espécie, como forma de inovação do mercado para fortalecer a economia da agricultura familiar. Segundo Cruz e Carvalho (2003) a caracterização morfométrica de frutos pode fornecer informações de modo a permitir diferenciar espécies do mesmo gênero no campo.

Apesar da palmeira se estabelecer na forma de maciços vegetais de grandes dimensões, atualmente o sistema de produção restringe-se basicamente ao agroextrativismo, portanto, é importante alertar para o risco da exploração predatória, que pode levar Á perda de biodiversidade pela erosão genética; sendo necessário que a obtenção de biodiesel da macaúba tome proporções de cadeia para que se obtenha escala de produção, variabilidade e sustentabilidade (MENCARINI, 2009).

As palmeiras oleíferas são consideradas espécies potenciais de alto rendimento, às quais não se tem domínio tecnológico, diferentemente das espécies oleaginosas convencionais, como soja, girassol, canola e algodão. Neste contexto é sugerida a criação do PROPALM - Programa 
de incentivo à Produção de Palmeiras Oleíferas para a Produção de Óleos e Produtos da Agroenergia em áreas brasileiras (DURÃES, 2010).

Devido aos benefícios da macaúba e a preocupação com as questões ambientais, substituir o que resta dos biomas brasileiros por mais monoculturas de plantas exóticas, existindo altos potenciais nativos, não parece ser a estratégia mais eficiente para levar o Brasil crescentemente à independência ao petróleo. Uma das alternativas seria estimular sistemas agroflorestais consorciando nativas e exóticas, arbustos, árvores e palmeiras (a serem substituídas à medida que os estudos sobre as nativas, e a tecnologia associada, avancem). Para tanto, é necessário desenvolver programas de melhoramento genético, para diminuir altura das plantas, eliminar espinhos, encontrar materiais mais produtivos e desenvolver tratos culturais, sendo esta a melhor contribuição para o controle das mudanças climáticas e para a preservação do meio ambiente (ROSCOE, 2006).

Verifica-se que esta palmeira tem grande potencial de implantação em território brasileiro, no entanto, nota-se ausência de informações botânicas, ecológicas e agronômicas que possibilitam a implantação de sistemas de cultivo ou manejo sustentável desta espécie (LORENZI, 2006).

\section{CONSIDERAÇÕES FINAIS}

A macaúba apresenta todas as características para despontar na produção de biocombustível, pois é uma cultura de elevada sustentabilidade e de produção via extrativismo familiar, além de, ser encontrada em praticamente todas as regiões do Brasil.

A diversidade de macaúba encontradas nas regiões brasileiras aliada ao seu potencial para produção de agroenergia e coprodutos, evidencia a necessidade de estudos para alçar o seu desenvolvimento. Portanto, fazem-se necessários estudos destinados a esclarecer não só a importância dessa cultura, mas ainda, os mecanismos que envolvem sua produção e extração de óleo.

\section{REFERÊNCIAS}

ALBUQUERQUE, C. J. B.; BRANT, R. S.; ROCHA, G. R.; JARDIM, R. R. Seletividade de herbicidas para o pinhão manso. In: Congresso Brasileiro de Mamona - Energia e Ricinoquimica, 3. Resumos... Salvador: SEAGRI: Embrapa Algodão, 2008.

ANDRADE, M. H. C.; VIEIRA, A. S.; AGUIAR, H. F.; CHAVES, J. F. N.; NEVES, R. M. P. S.; MIRANDA, T. L. S.; SALUM, A. Óleo do fruto da palmeira macaúba - Parte I: uma aplicação potencial para indústrias de alimentos, fármacos e cosméticos. In: Encontro brasileiro sobre tecnologia na indústria química (II ENBTEQ), 30. Resumos... São Paulo: ABEQ, 2006.

BANDEIRA, F. S. Cultivo in vitro e embriogênese somática de embriões zigóticos de macaúba (Acrocomia aculeata (Jacq.) Loddiges). 2008. 92 f. Tese (Doutorado 
em Ciência Florestal) - Curso de Pósgraduação em Ciência Florestal, Universidade Federal de Viçosa, Minas Gerais.

BARRETO, S. M. P. Avaliação da torta de macaúba na alimentação de caprinos. 2008. 74 f. Dissertação (Mestrado em Agroecologia) - Instituto de Ciências Agrárias da Universidade Federal de Minas Gerais, Montes Claros.

BHERING, L. Macaúba: matéria prima nativa com potencial para produção de biodiesel. Embrapa, p. 1-4, 2009. Disponível em: http://www.cnpae.embrapa.br/search? searchasletext =macauba. Acesso em: 02 jan. 2011.

BICALHO, E.M.; CARVALHO, M.; MOTOIKE, S.Y.; PAES, J.M.V. Propagação da macaúba: ciência e desafio. Informe Agropecuário, v. 32, n. 265, p. 16-19, 2011.

BIODIESELBR. Agricultura familiar, emprego e o lado social do biodiesel. 2006. Disponível em:

http://www.biodieselbr.com/biodiesel/social /aspectos-sociais.htm. Acesso em: 02 jan. 2011.

BRASIL. Ministério da Agricultura, Pecuária e Abastecimento. Anuário estatístico da agroenergia. Brasília: Mapa/ACS, 2009. 160p.

COSTA, C. J.; MARCHI, E. C. S. Germinação de sementes de palmeiras com potencial para produção de agroenergia. Informativo Abrates, v.18, n. 1,2,3, p.39-50, 2008.

CRUZ, E. D.; CARVALHO, J. E. U. Biometria de frutos e sementes e germinação de curupixá (Micropholis cf.venulosa MART.\& EICHLERSapotaceae). Acta Amazônica, v.33, n.3, p.389-398, 2003.

http://dx.doi.org/10.1590/S0044-

$\underline{59672003000300005}$

DURÃES, F. O. M. Agroenergia para óleos e co-produtos: palmas para o biodiesel. 2010.
Disponível

em: http://www.diadecampo.com.br/zpublisher/ materiais/materia. $\quad$ asp?id=21382\& secao=colunas\%20assinadas\&rated=true.

Acesso em: 01 abr. 2010.

HIANE, P. A., BALDASSO, P. A.; MARANGONI, S.; MACEDO, M. L. R. Chemical and nutritional evaluation of kernels of bocaiuva, Acrocomia aculeata (jacq.) lodd. Ciência e Tecnologia de Alimentos, v.26, n.3, p.683689, 2006. http://dx.doi.org/10.1590/S0101$\underline{20612006000300031}$

HIANE, P. A.; RAMOS FILHO, M. M.; RAMOS, M. I. L.; MACEDO, M. L. R. Bocaiúva, Acrocomia aculeata (Jacq.) Lodd., pulp and kernel oils: characterization and fatty acid composition. Brazilian Journal of Food Technology, v.8, p.256-259, 2005.

LORENZI, G. M. A. C.; NEGRELLE, R. R. B. Acrocomia aculeata (Jacq.) Lood. ex. Mart.: aspectos ecológicos, usos e potencialidades. Visão Acadêmica, Curitiba, v.7, n.1, 2006.

LORENZI, H. Árvores brasileiras: manual de identificação e cultivo de plantas arbóreas nativas do Brasil. Nova Odessa, SP: Plantarum. v.1, 4 ed. 2002. 288p.

LORENZI, G. M. A. C. Acrocomia aculeata (Jacq.) Lodd. ex Mart. - Arecaceae: bases para o extrativismo sustentável. 2006. 166 f. Tese (Doutorado em Produção Vegetal), Universidade Federal do Paraná, Curitiba.

LLERAS, E.; CORADIN, L. Palmeras nativas como oleaginosas: situación actual $y$ perspectivas para América Latina. In: FORERO, L.E. (ed.), Informe del SeminárioTaller sobre Oleaginosas Promisorias, Asociación Interciencia, Asociación Colombiana para el Avance de la Ciencia, Bogotá. p.92-143. 1985.

MACHADO, C. A. C.; ARGANDONA, E. J. S.; HOMEM, G. R.; TOMMASELLI, M. A. G. Modelo de viabilização da produção do 
consórcio: macaúba (Acrocomia aculeata) e cana-de-açúcar (Saccharum officinarum). In: Encontro nacional de engenharia de produção, 30. São Carlos. Resumos... São Carlos: ENEGEP, p.1-11, 2010.

MANFIO, C. E.; MOTOIKE, S. Y.; RESENDE, M. D. V.; SANTOS, C. E. M.; SATO, A. Y. Avaliação de progênies de macaúba na fase juvenil e estimativas de parâmetros genéticos e diversidade genética. Pesquisa Florestal Brasileira, v.32, n.69, p.63-68, 2012. http://dx.doi.org/10.4336/2012.pfb.32.69.63

MENCARINI, M. L. Comparativo de elementos da sustentabilidade no sistema de produção da macaúba: agroextrativista, em relação ao implantado, para biodiesel. In: Congresso da rede brasileira de tecnologia de biodiesel, 3, 2009, Brasília. Resumos... p. 899-900.

MOLLET, M.; HERZOG, F.; BEHI, Y. E. N.; FARAH, Z.; Sustainable exploitation of Borassus aethiopum, Elaeis guianeensis and Raphia hookeri for the extraction of palm wine in Côte D'lvoire. Environment, Development and Sustainability, v.2, n.1, p.45-59, 2000. http://dx.doi.org/10.1023/A:1010035915512

MOTTA, P. E. F.; CURI, N.; OLIVEIRA-FILHO, A. T.; GOMES, J. B. V. Ocorrência de macaúba em Minas Gerais: relação com atributos climáticos, pedológicos e vegetacionais. Pesquisa Agropecuária Brasileira,, v.37, n.7. p.1023-1031, 2002.

http://dx.doi.org/10.1590/s0100$\underline{204 \times 2002000700017}$

NUCCl, S. M. Desenvolvimento, caracterização e análise da utilidade de marcadores microssatélites em genética de população de macaúba. 2007. $84 \mathrm{f}$. Dissertação (Mestrado em Genética, Melhoramento Vegetal e Biotecnologia) Instituto Agronômico de Campinas, São Paulo.
PEREIRA, L. M.; ANTONIASSI, A; MESQUISTA, D. L.; JUNQUEIRA, N. T. V.; CARGNIN, A. Rendimento em óleo e carotenóides de macaúba (Acrocomia Acculeata). In: $32^{\mathrm{a}}$ Reunião Anual da Sociedade Brasileira de Química. Resumos... Fortaleza, Sociedade Brasileira de Química, v.1, p.1323, 2009.

POUSA, G. P. A. G.; SANTOS, A. L. F.; SUAREZ, P. A. Z. History and policy of biodiesel in Brazil. Energy Policy, v.35, n.11, p.5393-5398, 2007.

http://dx.doi.org/10.1016/i.enpol.2007.05.01 $\underline{0}$

RAMOS, L. P.; SILVA, F. R.; MANGRICH, A. S.; CORDEIRO, C. S. Tecnologias de Produção de Biodiesel. Revista Virtual de Química, v.3, n.5, p.385-405, 2011. http://dx.doi.org/10.5935/1984$\underline{6835.20110043}$

RIBEIRO, L. M.; GARCIA, Q. S.; OLIVEIRA, D. M. T.; NEVES, S. C. Critérios para o teste de tetrazólio na estimativa do potencial germinativo em macaúba. Pesquisa Agropecuária Brasileira, v.45, n.4, p.361-368, $2010 . \quad$ http://dx.doi.org/10.1590/S0100$\underline{204 \times 2010000400003}$

ROLIM, A. A. B. Óleos vegetais: usos gerais. Informe Agropecuário, v.7, n.82, p.17-22, 1981.

ROSCOE, R. Biodiesel. Uma opção Emergente para a Agricultura em Mato Grosso do Sul. A lavoura, p.33, 2006.

SALIS, S. M.; MATTOS, P. P. Bocaiúva (Acrocomia aculeata) e do Carandá (Copernicia alba) no Pantanal. Comunicado Técnico 78. Corumbá, MS. 2009. Disponível em:

http://www.cpap.embrapa.br/publicacoes/o nline/COT78.pdf. Acesso em: 04 out. 2012.

SCARIOT, A.; LLERAS, E.; HAY, J. D. Flowrering and fruiting phenologies of the palm Acrocomia aculeata: patterns and 
consequences. Biotropica,, v.27, n.2, p.168173, 1995. http://dx.doi.org/10.2307/2388992

SCARIOT, A.; LLERAS, E.; HAY, J. D. Reproductive biology of the palm Acrocomia aculeata in Central Brazil. Biotropica, v.23, n.1, p.12-22, 1991. http://dx.doi.org/10.2307/2388683

SCHUCHARDT, U.; RIBEIRO, M. L.; GONÇALVES, A. R. A indústria petroquímica no próximo século: como substituir o petróleo como matéria-prima?. Química Nova, v.24, n.2, p.247-251, 2001. http://dx.doi.org/10.1590/S010040422001000200016

Organização das Nações Unidas (ONU). Disponível em: http://www.un.org/english/. Acesso em: 11 maio 2011.

SODRÉ, B. J. Morfologia das Palmeiras como meio de identificação e uso paisagístico. 2005. 62 f. Dissertação (Especialização em Plantas Ornamentais e Paisagismo), Universidade Federal de Lavras, Minas Gerais.

SUAREZ, P. A. Z.; MENEGHETTI, S. M. P. 70응 aniversário do biodiesel em 2007: evolução histórica e situação atual no brasil. Química Nova, v.30, n.8, p.2068-2071, 2007. http://dx.doi.org/10.1590/S0100-

\section{$\underline{40422007000800046}$}

SUAREZ, P. A. Z.; MENEGHETTI, S. M. P.; MENEGHETTI, M. R.; WOLF, C. R. Transformação de triglicerídeos em combustíveis, materiais poliméricos e insumos químicos: algumas aplicações da catálise na oleoquímica. Química Nova, v.30, n.3, p.667-676, 2007. http://dx.doi.org/10.1590/S0100$\underline{40422007000300028}$

SUAREZ, P. A. Z.; SANTOS, A. L. F.; RODRIGUES, J. P.; ALVES, M. B. Biocombustíveis a partir de óleos e gorduras: desafios tecnológicos para viabilizá-los. Química Nova, v.32, n.3, p.768-775, 2009. http://dx.doi.org/10.1590/S0100$\underline{40422009000300020}$

TEIXEIRA, L. C. Potencialidades de oleaginosas para produção de biodiesel. Informe Agropecuário, v.26, n.229, p.18-27, 2005.

WANDECK, F. A.; JUSTO, P. G. A macaúba, fonte energética e insumo industrial: sua significação econômica no Brasil. In: Simpósio Sobre o Cerrado, Savanas, 6., 1988, Brasília. Resumos... Planaltina: Embrapa-CPAC, 1988. p.541-577.

Universidade Federal de Viçosa - UFV (Viçosa - MG). Adauto Quirino de Sá Junior, Francisco de Assis Lopes, Mychelle Carvalho, Márcio Antônio da Rocha Oliveira \& Sérgio Yoshimitsu Motoike. Processo de germinação e produção de sementes pré-geminadas de palmeiras do gênero Acrocomia. BR $\mathrm{n}^{\circ} \mathrm{PI}$ 0703180-7 A2, 20 de julho de 2007, 10 de março de 2009. 